\title{
Portfólio: Desafio de Portar mais que Folhas: a Visão do Docente de Odontologia
}

\author{
The Portfolio System and the Challenge of \\ Carrying More than Classroom Notes: the \\ View of a Dentistry Professor
}

\author{
Franklin Delano Soares Forte ${ }^{I}$ \\ Liza Barreto Vieira ${ }^{I I}$ \\ Talitha Rodrigues Ribeiro Fernandes Pessoa \\ Claudia Helena Soares Morais Freitas ${ }^{I}$ \\ Maria de Lourdes da Silva Marques Ferreira ${ }^{I I I}$
}

PALAVRAS-CHAVE:
- Formação.
- Portfólio reflexivo.
- Avaliação formativa.
- Metodologias de
ensino-aprendizagem

KEYWORDS:

- Education.

- Reflexive portfolio.

- Formative evaluation.

- Teaching-learning methodology.

Recebido em: 08/10/2010

Aprovado em: 24/11/2010

$25 \frac{\text { REVISTA BRASILEIRA DE EDUCAÇÃO MÉDICA }}{36(1, \text { Supl. 2) :25-32; 2012 }}$
${ }^{I}$ Universidade Federal da Paraíba, João Pessoa, PB, Brasil.

"I Escola Nacional de Saúde Pública Sergio Arouca, Rio de Janeiro, RJ, Brasil.

III Universidade Estadual Paulista "Júlio de Mesquita Filho". Faculdade de Medicina de Botucatu. 


\section{INTRODUÇÃO}

Em 2002, foram promulgadas as Diretrizes Curriculares Nacionais pelo Ministério da Educação, desencadeando mudanças na formação de profissionais da saúde. Esse movimento tem disparado reflexão sobre as propostas formativas que envolvem conceituação, modelos, desafios, posturas e olhares teórico-metodológicos do processo de ensino-aprendizagem. Tal proposta está tendo impacto sobre a organização dos currículos de graduação de muitas universidades brasileiras ${ }^{1}$.

A elaboração de relevantes movimentos educativos coloca o homem no centro do processo de aprendizagem com vistas à construção da cidadania. Isso ocorre não só no que se refere às evidências no diagnóstico, cuidado, tratamento, prognóstico, etiologia e profilaxia das doenças e agravos, mas também em relação ao desenvolvimento de um cuidado em saúde com base nos problemas de sujeitos, famílias e comunidade, a fim de favorecer a participação popular na tomada das decisões dos serviços de saúde e da autonomia nesse processo ${ }^{2,3}$.

O Projeto Pedagógico do Curso (PPC) de Odontologia da Universidade Federal da Paraíba (UFPB) foi aprovado em 2002 e apoia-se na proposta das Diretrizes Curriculares Nacional (DCN) para o curso. O objetivo é a formação de um profissional generalista e humanista, com capacidade crítica, reflexiva, para atuar em todos os níveis da atenção, compreendendo o contexto social, cultural e econômico da população, pautando sua atuação na transformação da realidade em benefício da sociedade. A formação do profissional com esse perfil exige a compreensão da complexidade do processo saúde-doença das populações ${ }^{1}$.

No final de 2005, o curso de Odontologia da UFPB aprovou, junto aos Ministérios da Saúde e da Educação, o Pró-Saúde. Embora o PPC estivesse aprovado desde 2002, muitas eram as dificuldades de sua implementação. Assim, a partir do incentivo do Pró-Saúde, diversos movimentos foram disparados, seja na orientação teórica e pedagógica - como capacitação de docentes e trabalhadores da rede em novas metodologias de ensino -, seja nos cenários de prática na estruturação da rede de saúde - com equipamentos e insumos importantes para a formação profissional e a produção do cuidado integral em saúde.

Durante os dois primeiros anos do curso de Odontologia da UFPB, o estudante tem vivências na Atenção Primária à Saúde nas áreas de abrangência das Unidades de Saúde da Família em João Pessoa, Paraíba. As discussões perpassam questões que abrangem desde a compreensão ampliada do processo saúde-doença, políticas públicas de saúde e de saúde bucal, humanização e acolhimento nos serviços de saúde, passando pela Estratégia Saúde da Família e o Programa de
Agentes Comunitários de Saúde, até o processo de trabalho em saúde e suas tecnologias e a educação em saúde.

As atividades são desenvolvidas nos equipamentos sociais (creches, unidades de educação infantil, igrejas, rádios comunitárias, centros de convivência de idosos, programas de erradicação do trabalho infantil, praças, etc.) das áreas de abrangência das Unidades de Saúde da Família, a fim de priorizar as ações de promoção e prevenção em saúde e trabalhos em equipe que utilizam metodologias ativas. Ao final de cada vivência, os docentes e trabalhadores da rede de saúde reúnem-se com os estudantes para a avaliação da experiência. A proposta da avaliação é que se realize uma análise de caráter qualitativo, de forma contínua, que permita a fala de cada ator envolvido para o diagnóstico da situação, levando ao planejamento e reorientação do processo de construção das vivências.

Em função da adoção das metodologias ativas como condutoras do processo de ensino-aprendizagem, a avaliação geral dos componentes foi repensada, com o objetivo de encontrar alternativas para a construção de dados e análises da prática pedagógica com base nos referenciais do PPC. Pensar uma avaliação que superasse as formas tradicionais e, ao mesmo tempo, colocasse a inserção dos estudantes nesse processo como sujeito autônomo, corresponsável pela aprendizagem, era o que se pretendia. Assim, nesse momento, pensou-se no portfólio como ferramenta capaz de atender a essas questões. O portfólio, como instrumento de reflexão crítica sobre a prática, evidencia potencialidades e fragilidades no processo de condução do ensino, nas vivências em campo e, de certa forma, democratiza os caminhos a serem percorridos $4,5,6,7,7,9,10$.

Dessa forma, e nesse cenário de novas abordagens dos conhecimentos, com base no perfil do egresso, competência, habilidades e atitudes, o portfólio surge como metodológica de avaliação e acompanhamento dos estudantes. Ele é entendido aqui como instrumento de organização do eixo de trabalho pedagógico, de acompanhamento e de avaliação constantes das vivências e do processo de ensino-aprendizagem ${ }^{11}$. O portfólio é um espaço de coleção de registros do aprendizado dessa trajetória em um dado momento. O desafio está em recriar esse espaço para além da coleção de folhas, no qual o estudante passa a sentir-se livre para recriar e pontuar, segundo seus valores e impressões, os trabalhos desenvolvidos em equipe ou em estudo autodirigido 8 .

Esse instrumento de reflexões das vivências é elaborado por meio da construção pessoal e profissional dos discentes e docentes envolvidos. Assim, a cada leitura e releitura, as reflexões dão espaço para mais mudanças de atitudes e ações. Dessa forma, o educando tem autonomia o tempo todo para se expressar pelas diversas linguagens, como: poesias, narra- 
tivas, figuras, fotos e outras formas quaisquer de expressão, tendo a motivação e a vocação como pontos de partida. Nesse caminho, o estudante vai se descobrindo, apoiado nas vivências, nos valores trazidos e no auxilio dos docentes ${ }^{4,5,6,7,7,9,10}$.

Logo, o objetivo deste estudo foi compreender a percepção dos professores do curso de Odontologia da Universidade Federal da Paraíba sobre a aplicação, a reflexão e o processo de ensino-aprendizagem do portfólio enquanto estratégia pedagógica reflexiva, servindo como procedimento de avaliação e acompanhamento dos estágios supervisionados da Saúde Coletiva.

\section{PERCURSO METODOLÓGICO}

Inicialmente, o projeto de pesquisa foi apresentado sob número de protocolo 368/09, FR 300724, ao Comitê de Ética em Pesquisa com Seres Humanos do Hospital Universitário da Universidade Federal da Paraíba, sendo aprovado na reunião do dia 24/11/2009. Foram observadas a Resolução 196/96 do Conselho Nacional de Saúde e a Declaração de Helsinki.

A metodologia adotada se caracteriza por uma abordagem indutiva, com procedimento descritivo e comparativo, com técnica de observação direta intensiva, tendo como base metodológica a pesquisa qualitativa para a construção e análise dos dados ${ }^{12}$. A opção foi a do grupo focal, o qual se baseia em uma estrutura mais flexível com o propósito de trazer à tona as significações dos atos refletidos nas relações pessoais e nas estruturas sociais que se modificam conforme a intervenção dos sujeitos envolvidos, permitindo a elaboração de ideias e de conceitos fundamentados em valores, expectativas e atitudes moderadas por um sujeito ${ }^{13}$.

Os estágios supervisionados do curso de Odontologia da Universidade Federal da Paraíba têm como objetivo aprimorar as vivências na atenção básica nas áreas de abrangência das USFs no município de João Pessoa, tendo como orientação teórica as metodologias ativas. Os cenários de prática são os equipamentos sociais existentes no território das USFs. Os atores nesse movimento são os estudantes, docentes e trabalhadores da rede de serviço de saúde, que articulam ações intersetoriais com outros campos de saber e de competências presentes em outras áreas do conhecimento, sobretudo possibilitando a aproximação dos estudantes com os contextos socioeconômico e cultural das famílias e da comunidade. Desde 2008, os portfólios foram adotados como ferramenta de acompanhamento e avaliação dos estudantes nos componentes curriculares da Saúde Coletiva.

O cenário da pesquisa foi a Universidade Federal da Paraíba, sendo incluídos no estudo cinco docentes dos Estágios Supervisionados I ao IV dessa Instituição, os quais assinaram o Termo de Consentimento Livre e Esclarecido. O grupo de professores foi intencionalmente selecionado em função do uso do portfólio como instrumento pedagógico de auxílio no acompanhamento e avaliação dos estudantes nos componentes curriculares de estágios supervisionados em Saúde Coletiva. A idade dos docentes variou entre 28 a 35 anos de idade.

Como já ressaltado, para a análise qualitativa foi utilizado o grupo focal como técnica de pesquisa, pois ele permite conhecer com maior profundidade as percepções, valores, costumes, crenças, comportamentos e as representações em torno do objeto de estudo ${ }^{14}$, sendo mediado por um moderador. Cabe destacar que as discussões foram orientadas por um roteiro e registradas em áudio (gravadas em mp5) e por escrito, para contextualização da percepção dos participantes, considerando as seguintes dimensões: conceituação de portfólio; contribuição do portfólio para a formação profissional; portfólio como instrumento de avaliação (potencialidades e dificuldades).

Foram realizados dois encontros com os docentes na mesma Universidade entre os meses de novembro e dezembro de 2009, utilizando as seguintes questões norteadoras:

1) O que é portfólio?

2) Quais as dificuldades enfrentadas por você nas leituras dos portfólios?

3) Quais as dificuldades encontradas na implantação dessa forma de acompanhamento e avaliação? Realmente está avaliando?

4) Como potencializar esse instrumento?

5) Quais as suas sugestões?

Posteriormente a essa fase, as entrevistas foram transcritas pelo pesquisador, que utilizou o programa Microsoft Office Word 2003 para o sistema Microsoft Windows XP Professional e, na sequência, foi realizada a leitura-análise exaustiva das transcrições.

Para interpretação dos dados, utilizou-se a proposta da análise de conteúdo, adotando categorias predefinidas, destacadas no parágrafo anterior, e categorias que foram definidas, a partir da recorrência nas falas dos entrevistados. Dessa for$\mathrm{ma}$, as entrevistas foram transcritas para leitura exaustiva do material coletado, procurando ordenar o conteúdo, sendo a releitura muitas vezes necessária ao material, para organização dos relatos e das observações ${ }^{15}$. Assim, foram estabelecidas as categorias com base no referencial teórico pesquisado e no roteiro da entrevista, como também foram associadas novas categorias, a partir da repetição nas falas dos sujeitos da pesquisa.

\section{RESULTADOS E DISCUSSÃO}

Neste capítulo estão dispostas as falas considerando as seguintes categorias temáticas: concepção e uso do portfólio; dificuldades; e potencialidades. 


\section{CONCEPÇÃO E USO DO PORTFÓLIO}

No que se refere ao conceito de portfólio, a maioria dos docentes sinalizou de forma positiva sua conceituação como ferramenta pedagógica. O portfólio é um importante gerador de reflexões das vivências nas práticas dos estágios, ancorado no conhecimento e na elaboração das competências profissionais propostos no PPC e na ementa dos componentes curriculares, além de ser uma experiência de vida.

\footnotetext{
“... acompanhar o estudante em suas reflexões das vivências... assim destaco o papel que o portfólio tem de trabalhar de forma individual..."

“... portfólio é uma maneira de compreender a atividade realizada a partir de reflexões, qual foi o conteúdo trabalhado?..."

“... o portfólio mostra as percepções, impressões e as subjetividades de cada aluno, é um instrumento que permite a expressão dessas percepções individuais... eles (os estudantes) conseguem captar e expressar no portfólio... resgata, não deixa que se perca e assim podemos ler as dificuldades, os desafios, as potencialidades..."
}

O portfólio é considerado como instrumento para avaliação e acompanhamento, mas também como eixo organizador do trabalho pedagógico ${ }^{7,11}$. Tanji e Silva $(2008)^{16}$ destacaram em sua pesquisa o papel que o portfólio tem de potencializar as reflexões das práticas vividas e a maneira como esse instrumento assegura a construção do conhecimento não só de caráter profissional, mas também pessoal. Esse processo elaborativo de reflexões constantes sobre a própria prática irá refletir não só no educando, como também no educador. As leituras feitas pelos estudantes, no sentido de aprofundamento de questões teóricas trabalhadas em sala de aula, quer seja na discussão de situações-problema, como de relatos de práticas, quer seja nas vivências de campo, nos espaços sociais do território, favorecem os processos criativos de reflexão registrados no portfólio. Essa prática pedagógica auxilia na tomada de decisões e na elaboração de propostas e conceitos ${ }^{7}$.

A proposta de trabalho pedagógico dos estágios supervisionados é a metodologia ativa, nesse contexto, práticas avaliativas também inovadoras devem ser adotadas, no sentido de valorizar a reflexão sobre a prática ${ }^{17,18}$. O cenário de prática dos estágios são os territórios das USFs no município de João Pessoa, na Paraíba, em uma parceria entre a IES formadora e a prestadora de serviço de saúde, que é o município. Essa articulação exige constante pactuação entre a gestão e a prestadora dos serviços de saúde, assim como da instituição formadora. Esse movimento é importante para uma coerência entre a orientação teórica e a prática assistencial.
Essa é uma estratégia de aproximação da formação profissional com a realidade socioeconômica e cultural em que o estudante está inserido. Para isso, valoriza-se o trabalho em equipe junto à comunidade, com vistas aos pilares da educação moderna: aprender a aprender, aprender a ser, aprender a conhecer e aprender a fazer, na perspectiva do educando como sujeito ativo de seu processo de formação ${ }^{19}$.

O portfólio possibilita a construção teórica, a fim de organizar as ideias e atuar como prática avaliativa desse processo. Optou-se pelo portfólio por acreditar que o cirurgião-dentista elabora e constrói sua autonomia enquanto se forma, conforme competência proposta pelas Diretrizes Curriculares Nacionais para o curso de Odontologia. A autonomia auxilia na tomada de decisões e no gerenciamento e administração de serviços, outras duas competências apontadas pelas DCN ${ }^{1}$.

Além disso, o portfólio foi considerado uma das formas de se realizar a avaliação formativa do processo de ensino-aprendizagem, em função de seus efeitos positivos. Permite ao professor verificar se houve entendimento do que foi discutido, partilhar saberes e experiências, perceber a capacidade de elaboração de ideias e conceitos com o suporte das leituras complementares, de resolver problemas, com vistas ao alcance de competências e habilidades específicas de cada estágio supervisionado ${ }^{11,17,20}$

O portfólio baseia-se no registro das atividades vivenciadas em sala de aula ou de campo, desenvolvidas em equipe com a ajuda de trabalhadores da rede de saúde do município, conforme já comentado. Essa prática permite não só o detalhamento documentado dos conhecimentos adquiridos, mas também a reflexão de avanços e desafios, apontados na direção de propostas.

É preciso liberdade para expressar-se, fazendo desses momentos a valiosa contribuição de ressignificar conceitos e práticas e aprofundar as leituras. Esse exercício facilita a elaboração de ideias que irão ser utilizadas na tomada de decisão. Por isso, a autonomia intelectual e condições adequadas de trabalho são imprescindíveis para o espaço de diálogo com o docente que o supervisiona ${ }^{11,17,18,20}$.

Os sentimentos de frustração nas histórias de cada um antes do curso, as incertezas com a opção da profissão, as dificuldades enfrentadas podem ser, de um lado, fatores bloqueadores na elaboração dos portfólios reflexivos, pois muitos não gostam de lembrar nem de expor sua trajetória pessoal8. Por outro, o portfólio mostra os processos de autoconhecimento, autorreflexão e amadurecimento ao longo da formação profissional.

Sá-Chaves $(2000)^{4}$ destacou o papel do portfólio no registro do cotidiano do estudante em formação e os reflexos 
em sua vida enquanto cidadão. É um desafio para o estudante o exercício de repensar sua prática, especialmente porque no ensino médio, e muitas vezes no curso de graduação, em outros componentes curriculares, a prática pedagógica ainda é cartesiana e as relações são verticais. A proposta de uso do portfólio é inovadora, pois procura práticas horizontalizadas de relações interpessoais, práticas participativas e inclusivas, tentando eliminar o autoritarismo e a condução pedagógica da aprendizagem centrada no professor ${ }^{11,17}$.

“... é uma grande demanda ler todos os portfólios o que exige tempo... tão escasso dentro de nossas atividades na Universidade... por outro lado, é preciso valorizar esse instrumento."

“... fazemos logo no início leituras iniciais sobre o portfólio que são uma forma de se apropriar do instrumento, mas é difícil no início... tem um processo em curso... eles (os estudantes) vão amadurecendo e fazendo conexões com as discussões em roda com os colegas e os profissionais da rede ou dos dirigentes dos espaços sociais e, assim, sugestões e reflexões sobre sua formação vão surgindo..."

Assim, Freire (1999 $)^{22}$ pontua que essa consciência reflexiva deve ser estimulada continuamente, especialmente diante de situações-problema ou relatos de práticas, quando existe a necessidade de aprender a refletir sobre sua própria realidade.

Foi preciso que o grupo de docentes se fundamentasse para o uso do portfólio. A estratégia utilizada foram leituras complementares, com discussões em roda, para entendimento coletivo do conceito, objetivo e proposta pedagógica.

“... Tinha dificuldades no início, era minha primeira experiência com esse sistema de avaliação... por isso fiz leituras complementares... o que fez com que eu também repensasse minha prática..."

Villas Boas $(2005)^{11}$ relatou também em seu trabalho essa necessidade apresentada pelo grupo de professores pesquisados na discussão do papel do professor, do aluno e da escola para o investimento na autonomia dos sujeitos com vistas à transformação. O desafio dessa proposta não está somente relacionado ao docente, mas também ao estudante. Esse instrumento é ainda pouco utilizado na educação superior ${ }^{8,20}$.

Nesse sentido, os docentes relatam a necessidade do retorno com registro das leituras aos estudantes, as quais geram, por um lado, provocações para mais questionamentos ou apontamentos, e, por outro, a valorização do que foi produ- zido por eles, criando um espaço dialógico de troca de ideias entre educando e educador.

“... os alunos esperam ler o que o professor refletiu sobre; o aluno se sente desvalorizado se o professor não ler... assim, embora seja uma demanda grande de leitura, acho importante as devolutivas aos alunos de forma personalizada, ou seja, a cada um uma resposta, uma intervenção..."

“... À medida que fazemos perguntas, reflexões, eles se esmeram para melhorar... quando não existem as devolutivas, eles (os estudantes) se sentem desvalorizados..." “... Liberdade como abertura, diálogo, que eles se sentem à vontade com a gente. Foram além desse limite. Mesmo os mais tímidos, conseguem transpor para o portfólio algumas reflexões... de vida pessoal, reflexões de seu passado de sua história de vida, vivências nas práticas na comunidade..."

“... sempre penso no papel de professor como provocador... de espaços dialógicos a partir dessa relação horizontalizada..."

“... a troca de saberes, os questionamentos são importantes para a formação, especialmente quando você é confrontado com a realidade diferente da sua... e isso acaba surgindo no portfólio..."

“... alguns alunos não enxergam a liberdade que têm no portfólio, não percebem que os registros podem ser textos com formatos distintos, discussão, música, poema, resenha de textos e já têm outros que expõem coisas íntimas da vida, e dividem aquele momento com o professor no portfólio..."

No caso dos estágios supervisionados, a construção do conhecimento é mediada e enriquecida pelos docentes, que, em contato individual ou no acompanhamento das vivências no território e nas avaliações nos pequenos grupos, facilitam as leituras dos portfólios e a retroação com novas informações e apontamentos na perspectiva de enriquecer esse processo ${ }^{20}$, orientando o modo de ser e de agir do cirurgião-dentista em formação ${ }^{23}$.

O docente auxilia o estudante nesse processo buscando a habilidade de avaliar seu próprio trabalho e o trabalho em equipe. Consequentemente, isso proporciona o exercício constante de pensar e repensar as vivências, avaliando-as em processo e sendo capaz de ajustar, quando necessário, o caminho para mudanças ${ }^{5,8,20}$.

O portfólio é percebido como uma ferramenta de acompanhamento e avaliação pelos docentes, embora muitas vezes traga ainda a percepção do conceito de práticas pedagógicas tradicionais. Esse entendimento precisa ser melhor explorado 
pelos educadores e educandos, pois as leituras dos portfólio pelos docentes geram inquietações, e esse processo de avaliação contínua é bem distinto da concepção tradicional de avaliações. Essas leituras oportunizam (re)pensar os caminhos do processo de ensino-aprendizagem, a partir da integração de seus elementos estruturantes (ementa, objetivos, conteúdo programático, metodologias de ensino e avaliação), como também permite que o estudante se posicione adotando postura crítica diante do vivenciado.

“... se a opção são as metodologias ativas; então, a avaliação também ser diferenciada é inerente a esse processo, a nossa opção foi o portfólio: o desafio de sair de registros mecânicos, como, por exemplo, quando vamos lendo, percebemos os relatos descritivos, e me pergunto até que ponto o estudante compreendeu qual era o objetivo do portfólio..."

“... eu tento identificar se houve reflexão sobre o tema, conexões com o vivido em sua história ou discutido em sala de aula e, nesse momento, tento estimulá-los e, por isso, escrevo para que ele reflita mais, faça mais críticas e sugestões..."

“... com o tempo eles vão amadurecendo, mais subjetividades aparecendo, identificação de um portfólio reflexivo e não de um diário..."

É importante diferenciar o portfólio do diário de campo, muitas vezes os conceitos são confundidos e, assim, adotados como prática. Nessa perspectiva, cabe ao docente examinar e discutir em equipe. O portfólio vai além do diário, permite o resgate da memória da trajetória de aprendizagem pelo estudante, nas vivências nos diversos cenários.

“... eu ainda sinto que alguns alunos não conseguem distinguir a diferença entre diário de campo e portfólio (...) às vezes são descritivos os relatos daquela atividade realizada..."

“... eles acabam confundindo uma narrativa descritiva com o registro dos portfólios. É tanto que ele começa falando no dia de hoje, no presente, se perdendo muito preso no hoje, sem fazer reflexão contextualizada...."

Assim, nos estágios supervisionados, o estudante tem a liberdade de incluir fotos, figuras, mapas, desenhos, poemas, comentários pessoais, ou seja, personalizar as rotas alternativas de reflexão, pois estas foram importantes como experiências. Dessa forma, são consideradas como produção do estudante as diversas formas de expressão de linguagem, sendo mais rico o portfólio quando isso aparece ${ }^{11}$.

\section{DIFICULDADES E POTENCIALIDADES}

Os docentes apontam também a dificuldade apresentada pelos estudantes na escrita, na redação do texto a partir do que foi vivenciado. Villas Boas $(2005)^{11}$ relatou, de um lado, também estranhamento, medo e insegurança por parte dos estudantes pesquisados; por outro lado, à medida que passava o tempo, o sentimento foi traduzido em descoberta de algo novo e prazeroso.

“... obrigatoriamente, eles (os estudantes) fazem de forma mecânica, ao longo do tempo, quando a gente vai fazendo as intervenções, pontuando e destacando momentos, entretanto, alguns insistem e permanecem sendo uma coisa menos reflexiva e mais repetitiva ou cumpridora de tarefa. E fico pensando se é esse o objetivo do portfólio..."

Ellis et al. (2006) 7 propõem a discussão prévia em grupo para envolver os atores nesse processo de uso do portfólio, assim acredita ser possível barreiras que direcionam o foco nos esforços de compreensão do uso da ferramenta, tanto por parte dos estudantes quanto dos profissionais envolvidos no processo.

A discussão do uso do portfólio nos componentes é relatada pelos docentes. É questionada a necessidade da produção de uma reflexão a cada dia. Talvez se houvesse liberdade para o registro de temas considerados importantes pelos educandos e educadores, esse tipo de avaliação fosse tida como uma estratégia de enfrentamento ou de elaboração de questões de aprendizagem. Uma questão simples sempre vem à tona: as notas ou o valor atribuído. Assim, é preciso dar novo sentido a essa "nota", valorizando as subjetividades e o exercício constante de pensar e repensar, a fim de elaborar novas práticas, saberes, ações, atitudes e conceitos ${ }^{7,22}$.

“... é preciso explicar inicialmente sobre o portfólio e sua razão de ser, as leituras iniciais ajudam muito, mas é preciso encontrar mais estratégias para explorar essa questão como processo de avaliação mesmo e diferenciado de um diário..."

“... eles (os estudantes) dizem: "é difícil escrever sobre mim..." e que não conseguem falar sobre si, que não têm potencial, nem sabem qual sua potencialidade... é preciso ser provocador para a reflexão e consequente ação..."

“... é preciso romper com o tradicional, tanto na forma de ensinar como aprender e também de avaliar e ser avaliado... acho que o desafio é e sempre será afinar o instrumento e oportunizar um olhar mais humanizado e acolhedor a esse jovem que se prepara para a vida profissional..." 
O portfólio apresenta-se como ferramenta potente no processo de ensino-aprendizagem, diferentemente da proposta tradicional de provas e exercícios rígidos. Por ser um instrumento novo para alguns, torna-se desafiador tanto para o educador como para o educando, exigindo do docente leituras complementares de aprofundamento do tema e ressignificação da prática pedagógica até então exercida ${ }^{7}$.

Conforme apontaram Silva e Tanji $(2008)^{8}$, seria interessante a participação dos estudantes nos critérios de qualidade e de parâmetros para a crítica de seu próprio trabalho. Assim, pode-se trabalhar na perspectiva da corresponsabilização do processo, sendo designado aos estudantes esse desafio em sua aprendizagem, selecionando os produtos dessa trajetória para elaborar autoanálise ${ }^{21}$.

Assim, conforme destacado anteriormente, a Universidade tem o desafio de formar profissionais cidadãos. Para isso, é importante colocar em prática as orientações das DCN e da Comissão Internacional da Educação e da Unesco, com os quatro pilares da educação com vistas à transformação da sociedade $\mathrm{e}^{1,19,22}$ e alcançar o que propõe o Pró-Saúde em seus eixos de reorientação teórica, diversificação dos cenários de prática e orientação pedagógica. A proposta do portfólio no curso de Odontologia vem ao encontro das necessidades de implantação de um projeto pedagógico aprovado na Universidade, cujo objetivo é a formação de cirurgiões-dentistas reflexivos, críticos, aptos para tomada de decisão nos diversos níveis de atenção em saúde e para que eles invistam na construção do Sistema Único de Saúde (SUS) no Brasil.

\section{CONCLUSÃO}

O portfólio é compreendido pelos docentes em dois eixos: reflexão e avaliação formativa das atividades dos estudantes, transformando muitas vezes o invisível em visível, expresso em diferentes linguagens. Sendo assim, o portfólio é visto pelos docentes como um facilitador da reconstrução e (re)elaboração de ideias, conceitos e valores, resgatando impressões e percepções e registrando a ampliação individual do que foi vivenciado em grupo.

As dificuldades enfrentadas nessa construção remetem à fragilidade na elaboração da comunicação escrita. Entendemos que as mudanças propostas com o uso de metodologias ativas e do uso do portfólio como instrumento de avaliação operam, de um lado, um processo às vezes longo e lento, exigindo a participação dos atores envolvidos para aprimoramento.

Por outro lado, os docentes apontam que houve avanço na proposta pedagógica de avaliação e reconhecem a importância do portfólio reflexivo para a formação profissional.

\section{REFERÊNCIAS}

1. Brasil. Resolução CNE/CES 3, de 19 de fevereiro de 2002. Institui Diretrizes curriculares Nacionais do Curso de Graduação em Odontologia.

2. Ceccim RB, Feuerwerker LMO. Quadrilátero da formação para a área da saúde: ensino, gestão, atenção e controle social. Physis. 2004 14(1): 41-65.

3. Moysés SJ. Políticas de saúde e formação de recursos humanos em Odontologia. Rev ABENO. 2004; 4(1): 30-7.

4. Sá-Chaves I. Os Portfólios reflexivos (também) trazem gente dentro. Reflexões em torno do seu uso na humanização dos processos formativos. Portugal: Ed. Porto, 2005.

5. Alvarenga GM. Portfólio: o que é e a que serve? Rev Olho Mágico 2009 [acesso em: 20 dez.2009];8(1):19-21. Disponível em: <http://www.ccs.uel.br/olhomagico/v8n1/ index.html>.

6. Bordenave JD, Pereira AM. Estratégias de ensino-aprendizagem. Petrópolis: ed. Vozes; 2005.

7. Ellis JS. et al. Tutor perceptions of the use of a reflective portfolio within a pastoral tutor system to facilitate undergraduate personal development planning. Eur J Dent Educ. 2006; 10(14): 217-225.

8. Silva CMSMD, Tanji S. o portfólio reflexivo: pareceres dos estudantes de enfermagem. Rev. Iberomericana de educación. 2008; 46(6): 1-10.

9. Marin MJS, Moreno TB, Moravcik MY, HigaI EFR, Druziani S, Francischetti I., Ilias M. O Uso do Portfólio Reflexivo no Curso de Medicina: Percepção dos Estudantes. Rev. Bras. Educ. Med. 2010; 34 (2): 191-198.

10. Silva RF, Francisco MA. Portfólio reflexivo: uma estratégia para a formação em medicina. Rev. Bras. Educ. Med. 2009; 33 (4): 562-570.

11. Villas Boas BMF. O portfólio no curso de pedagogia: ampliando o diálogo entre professor e aluno. Rev Educ Soc 2005; 26(90): 291-306.

12. Lakatos, Marconi, 2006

13. Minayo MCS. O desafio do conhecimento: pesquisa qualitativa em saúde. São Paulo: Ed. Hucitec, 2006.

14. Stewart DW, Shamdasani PN. Focus groups: theory and practice applied social research methods series. Sage, Newbury. 1990.

15. Bardin B. Análise de conteúdo. Lisboa: Ed. 70 LTDA, 2009.

16. Tanji S. Silva CMSLMD. As potencialidades e fragilidades do portfólio reflexivo na visão dos estudantes de enfermagem. Rev. enferm. UERJ 2008; 16(3): 392-8.

17. Araujo ES. O uso do portfólio reflexivo na perspectiva histórico cultural. In: 30aㅡ Reunião Anual da ANPED, 30., 2007, Caxambu. Anais... São Paulo, 2007. 
18. Mitre SM, Siqueira-Batista R, Girardi-de-Mendonça JM, Morais Pinto NM et al. Metodologias ativas de ensino-aprendizagem na formação profissional em saúde: debates atuais. Ciênc. saúde coletiva 2008; 13(suplem2): 21332144.

19. Delors J. Educação: um tesouro a descobrir. São Paulo: ed. Cortez, 1999.

20. Silva RF, Sá-Chaves I. Formação Reflexiva: representações dos professores acerca do uso de portfólio reflexivo na formação de médicos e enfermeiros. Interface: Comunic., Saúde, Educ. 2008; 12(27): 721-34.

21. Alves LP. Portfólios como instrumento de avaliação dos processos de ensinagem. GT: didática/n.04, UNERJ. Disponível em: http: / / www.anped.org.br. Acesso em: 20dez. 2009.

22. Secco LG, Pereira MLT. Formadores em odontologia: profissionalização docente e desafios político-estruturais. Cienc. Saúde Coletiva. 2004; 9(1): 113-20.

\section{CONTRIBUIÇÃO DOS AUTORES}

Franklin Delano Soares Forte participou da coordenação da pesquisa, coleta dos dados, interpretação e análise dos dados, redação e revisão final do manuscrito. Liza Barreto Vieira, Talitha Rodrigues Ribeiro Fernandes Pessoa e Claudia Helena Soares Morais Freitas, participaram da análise dos dados e redação do artigo. Maria de Lourdes da Silva Marques Ferreira orientou todas as etapas do estudo, colaborou na análise dos dados e participou da redação do manuscrito.

\section{CONFLITO DE INTERESSES}

Declarou não haver.

\section{ENDEREÇO PARA CORRESONDÊNCIA}

Franklin Delano Soares Forte

Rua Sebastião Azevedo Bastos, 714 ap. 1401

Manaíra - João Pessoa

CEP. 58038-491 PB 